\title{
EDITORIAL
}

\section{The black box of lung redox}

\author{
J. Hunt
}

The redox systems in the lung are complex, highly intercommunicative, and affect diverse aspects of lung physiology, immunology and cellular biology, and for all intents and purposes, they are essentially unmeasurable in vivo. Measurement of one component species of the redox systems in isolation, for example nitric oxide (NO), leaves one with little insight into the remainder of the biochemical processes. This unfortunately leaves researchers confident, but unable to fully prove, the extent to which redox disturbances are inherent to human lung diseases.

INCHINOSE et al. [1] in this issue of European Respiratory Journal, have in part overcome this hurdle. They measure only three components of the lung redox system (xanthine oxidase (XO), NO, and nitrotyrosine), by necessity leaving the remainder unassessed. However, they leverage a simple, although not randomised or placebo controlled, therapeutic intervention (treatment of humans with the XO inhibitor allopurinol) to show that in chronic obstructive pulmonary disease (COPD) the concentrations of these three redox components not only depend on each other, but can also be manipulated. Although not unexpected, it is gratifying that the theoretical underpinnings of many cell biology and biochemical experiments at the bench are shown to be relevant by such a clinical trial.

Measurement of fractional excretion of nitric oxide (FENO) has become an accepted method of monitoring inflammation in the lung. But what is really being assessed when FENO is measured? Working on the assumption that NO is provided to the exhaled air from the airway wall, it is clear that there are physiological factors which affect FENO, including expired flow (the lower the flow, the higher the FENO) [2], airway closure (more closure leads to more of the expired flow coming through fewer NO-producing airways, and thus lower FENO), and contribution from the upper airway. But more relevant to the airway chemist is how that NO is formed.

Initial formation of NO is primarily by action of isoforms of nitric oxide synthase (NOS). However, NOS is not the only source of $\mathrm{NO}$. Ingestion of nitrate $\left(\mathrm{NO}_{3}{ }^{-}\right)$-rich meals also leads to increased FENO, through bacterial nitrification reactions, specifically reduction of $\mathrm{NO}_{3}{ }^{-}$to nitrite $\left(\mathrm{NO}_{2}{ }^{-}\right)$, which upon protonation and redox reactions forms $\mathrm{NO}[3,4]$. However formed, NO functions as a direct actor in a seemingly limitless number of regulatory pathways, and importantly as a precursor molecule for other biologically active nitrogen oxides, including S-nitrosothiols (which perhaps are more important than NO as signalling molecules and regulators of cell biology and physiology) [5]. Because of the many and varied reactions, NO does not stay NO for long.

When authors say NO, sometimes they do not mean NO.

Division of Pediatric Respiratory Medicine, University of Virginia, Charlottesville, VA, USA

Correspondence: J. Hunt, Division of Pediatric Respiratory Medicine, Box 800386, University of Virginia, Charlottesville, VA 22908, USA. Fax: 1 4342435392. E-mail: jfh2m@virginia.edu.
Other oxides of nitrogen are important to consider as sinks and sources of $\mathrm{NO}$, and many of these have bioactivities in their own right (for example the S-nitrosothiols). The NOS isoforms also produce peroxynitrite (OONO-), which along with and through its conjugate peroxynitrous acid (HONOO), is a potent oxidising and nitrating agent (nitration is the addition of $\mathrm{NO}_{2}{ }^{+}$to a molecule, often a phenol such as tyrosine, in exchange for a proton $\left.\left(\mathrm{H}^{+}\right)\right)$[6]. If there are no immediately available targets to oxidise or nitrate, HONOO readily decomposes to what we think is relatively innocuous $\mathrm{NO}_{3}{ }^{-}$. Aside from the enzymatic process, rapid reaction of NO with superoxide $\left(\mathrm{O}_{2}^{-}\right)$also forms OONO-. Oxidation of $\mathrm{NO}$ can also form $\mathrm{NO}_{2}^{-}$, which then serves as a storage pool for the following: 1) NO; 2) condition-dependent nitration or nitrosylation equivalents; and 3) substrates for enzymatic nitration of proteins [7]. These reactions also depend on the availability of the smallest of all molecules, $\mathrm{H}^{+}$. The summation of these various biochemical processes that produce and consume NO, combined with the previously mentioned physiological variables, is what FENO assesses. However, it is all the underlying chemical processes that contribute to determining FENO that matter for lung biology, and not the leftover NO that happens to escape from the airways as exhaust. Those underlying processes in vivo remain locked within the black box.

Efforts are being made to assess redox activity in the lung in health and disease states. Papers that identify evidence of oxidative burden in the lung based on assays in various tissue or fluid samples are increasingly common. Increased exhaled breath levels of hydrogen peroxide, isoprostanes, ethane, pentane and others are purported evidence of increased oxidative burden. Others study induced sputum, bronchoalveolar lavage fluid and occasionally biopsy material for various indicators of oxidative burden, such as ratios of oxidised to reduced glutathione.

But what is oxidative burden? Does it mean that there is more oxidation occurring than reduction? Certainly not, as oxidation and reduction are always balanced. But oxidation does consist of hungry electronegative compounds greedily consuming available negative charge, and it is a burden if the electronegative compounds are borrowing electrons from molecules that we would rather keep as they are, such as enzymes and cell membrane lipids. Oxidative stress is a condition in which a greater than normal amount of strong electron receptors are being generated, and they attack molecules that are best left undisturbed. $\mathrm{O}_{2}^{-}$, hydrogen peroxide, HOONO, and, as the common intermediary, hydroxyl radical, are some oxidants of relevance.

$\mathrm{O}_{2}^{-}$is always in the cellular environment, and functions in some manner as a signaling molecule $[8,9]$. As discussed in the paper by ICHINOSE et al. [1], there are multiple mechanisms to form $\mathrm{O}_{2}{ }^{-}$, one of which is $\mathrm{XO}$. The authors identified that in subjects with COPD, the $\mathrm{XO}$ activity in induced sputum was four-fold higher than controls, and that this activity was effectively reduced by allopurinol. Importantly, it becomes clear that $\mathrm{XO}$ is more than just a minimal source of 
airway $\mathrm{O}_{2}$ - in COPD, because allopurinol administration substantially affected levels of some of the compounds with which $\mathrm{O}_{2}$ - would otherwise react. Specifically, administration of allopurinol led to decreased induced sputum nitrotyrosine immunostaining, and higher exhaled NO. Thus, at least a small portion of the nitrogen oxides that, through oxidation, would otherwise have been in a form capable of nitrating proteins, is instead left as uncharged gaseous molecules that can be exhaled. These data are consistent with the notion that $\mathrm{O}_{2-}$ produced by $\mathrm{XO}$ is relevant at the very least to our measures of FENO.

However, it may go further than that. Nitration of proteins may well be more than just a marker for the presence of OONO-. Indeed, chemically, nitration may occur through OONO- formation and/or protonation, $\mathrm{NO}_{2}$ - acidification, or through nitrogen dioxide formed from $\mathrm{NO}$ reacting with $\mathrm{O}_{2}$. Perhaps more importantly in some settings, nitrotyrosine may reflect the activity of neutrophil myeloperoxidase and eosinophil peroxidase [7]. For these reasons, it is not surprising that nitrotyrosine seems to be present in diverse tissues primarily in inflammatory disease states in which $\mathrm{pH}$ is low, NO production is high and polymorphonuclear leukocytes are common.

Unlike nitrosylation (exchange of $\mathrm{NO}^{+}$for $\mathrm{H}^{+}$), there is as yet no clear proof that nitration of proteins is a regulated process. There is evidence that nitration affects enzyme function, and reason to suspect that kinase pathways might be interfered with or mimicked [10] if the signalling molecules have their tyrosine residues nitrated. Perhaps more interesting is the uninvestigated concept that nitrotyrosine has chemical characteristics very similar to dinitrophenol [11], dinitrochlorobenzene and dozens of other compounds that are welldescribed haptens. Indeed to the cells of adaptive immunity, these molecules may appear identical. Maybe these molecules are haptens because they look like nitrotyrosine. The question is: could tyrosine nitration caused by innate processes involving $\mathrm{NOS}, \mathrm{pH}, \mathrm{O}_{2^{-}}$, and neutrophil myeloperoxidase subsequently activate acquired immune responses against nitrated endogenous proteins?

In chronic obstructive pulmonary disease, superoxide is overproduced and nitrotyrosine abounds. It is likely that nitric oxide is overproduced as well, yet there is less nitric oxide in human exhaled air than there otherwise would be because it is consumed in oxidative processes. These processes can indeed be blocked. Although it remains to be determined if nitration is causally relevant to human lung disease in vivo, ICHINOSE et al. [1] have provided sound evidence that it is relevant at least to exhaled nitric oxide measures. Additionally, they have reported a simple human system that has given clinical credence to many preceding redox studies at the bench. Nonetheless, because of difficulty in measuring them all at once, the formation and fate of each molecule of the redox systems of the lung in vivo remains uncertain.

\section{References}

1. Ichinose $\mathrm{M}$, Sugiura $\mathrm{H}$, Yamagata $\mathrm{S}$, et al. Xanthine oxidase inhibition reduces reactive nitrogen species production in COPD airways. Eur Respir $J$ 2003; 22: 457-461.

2. Silkoff PE, McClean PA, Slutsky AS, et al. Marked flowdependence of exhaled nitric oxide using a new technique to exclude nasal nitric oxide. Am J Respir Crit Care Med 1997; 155: 260-267.

3. Zetterquist W, Pedroletti C, Lundberg JO, Alving K. Salivary contribution to exhaled nitric oxide. Eur Respir $J$ 1999; 13: 327-333.

4. Gaston B, Ratjen F, Vaughan JW, et al. Nitrogen redox balance in the cystic fibrosis airway: effects of antipseudomonal therapy. Am J Respir Crit Care Med 2002; 165: 387390.

5. Foster MW, McMahon TJ, Stamler JS. S-nitrosylation in health and disease. Trends Mol Med 2003; 9: 160-168.

6. Ischiropoulos $\mathrm{H}, \mathrm{Zhu} \mathrm{L}$, Chen $\mathrm{J}$, et al. Peroxynitritemediated tyrosine nitration catalyzed by superoxide dismutase. Arch Biochem Biophys 1992; 298: 431-437.

7. van der Vliet A, Eiserich JP, Halliwell B, Cross CE Formation of reactive nitrogen species during peroxidasecatalyzed oxidation of nitrite. A potential additional mechanism of nitric oxide-dependent toxicity. $J$ Biol Chem 1997; 272: 7617-7625.

8. Babior BM. Superoxide: a two-edged sword. Braz J Med Biol Res 1997; 30: 141-155.

9. Biological signalling using superoxide and nitric oxide radicals. 98th conference of the Society of Biological Chemistry. Bavaria, Federal Republic of Germany, October 14-17, 1992 (Abstracts). Biol Chem Hoppe-Seyler 1992; 373: 735-746.

10. Mallozzi C, Di Stasi AM, Minetti M. Nitrotyrosine mimics phosphotyrosine binding to the $\mathrm{SH} 2$ domain of the src family tyrosine kinase lyn. FEBS Lett 2001; 503: 189-195.

11. Beckman JS, Chen J, Lschiropoulos H, Crow JP. Oxidative Chemistry of Peroxynitrite. Methods Enzymol 1994; 233: pp. 229-240. 